\title{
Determination of the Minimum Antenna Mast Height with Nonzero Path Inclination: Method II
}

\author{
Fidelis Osanebi Chucks Nwaduwa ${ }^{1}$, Wali Samuel ${ }^{2}$, Elsie Chidinma Anderson ${ }^{1}$ \\ ${ }^{1}$ Department of Electrical/Computer Engineering, Port Harcourt Polytechnic, Rumuola, Port Harcourt, Nigeria \\ ${ }^{2}$ Department of Electrical/Electronic and Computer Engineering, University of Uyo, Uyo, Nigeria
}

\section{Email address:}

samwalliuy@yahoo.com (W. Samuel)

\section{To cite this article:}

Fidelis Osanebi Chucks Nwaduwa, Wali Samuel, Elsie Chidinma Anderson. Determination of the Minimum Antenna Mast Height with Nonzero Path Inclination: Method II. American Journal of Software Engineering and Applications. Vol. 6, No. 2, 2017, pp. 44-48. doi: 10.11648/j.ajsea.20170602.16

Received: January 3, 2017; Accepted: January 18, 2017; Published: June 12, 2017

\begin{abstract}
In this paper, a second method for the determination of the minimum antenna mast height for line of site wireless communication link with nonzero path inclination and with known height of one of the antennas is presented. In the first method,(not presented here), none of the antenna height is known. In this second paper, the height of one of the antenna is known, particularly, the antenna that is above the maximum obstruction height. This places further constraint in the determination of the minimum antenna mast height for the lower antenna. In this paper, both the mathematical models and the algorithm are presented along with sample numerical example using path profile data for a $3 \mathrm{GHz}$ microwave communication link with path length of $38.8876 \mathrm{~km}$. The know antenna height is $20 \mathrm{~m}$ above the maximum height of the tip of the obstruction which is found to be $146.62 \mathrm{~m}$ at a distance of $14306.98 \mathrm{~m}$ from the transmitter. From the result, the receiver antenna height is $166.6 \mathrm{~m}$ and transmitter antenna height is $135.35 \mathrm{~m}$ whereas, the transmitter antenna mast height is $45.51 \mathrm{~m}$ while the receiver antenna mast height is $117.1 \mathrm{~m}$ the path inclination is 0.804 . The ideas presented in this paper are particularly useful when a line of sight link is to be extended from an existing transmitting point.
\end{abstract}

Keywords: Microwave Communication Link, Path Inclination, Elevation Profile, Antenna Mast Height, Line of Sight Communication

\section{Introduction}

In wireless communication systems, Line Of Site (LOS) communication is a form of communication used when the signal, such as microwave, can travel in a straight line [1-5] In that case, the transmitter and receiver antennas are raised and aligned to each other above the surrounding obstructions in the signal path. In order to determine the minimum antenna height for clear line of sight certain terrain and network parameters are considered; namely, the terrain elevation profile, the earth bulge, the obstruction height, the signal frequency, radius of the Fresnel zone, among others [6-11].

Basically, determination of the minimum antenna mast height is to minimize cost of construction, installation and maintenance of the mast. The higher the mast, the higher the cost. When installing a fresh LOS link, the minimum height of the transmitter and the receiver antennas need to be determined from the available link and terrain parameters. In that case, none of the antenna height is known. The approach to determining the minimum antenna mast heights in such case is presented in method I. In this paper, the method II is presented for determination of the antenna mast height when the path inclination is not equal to zero and the height of one of the antennas is known, particularly, the antenna that is above the maximum obstruction height. This places further constraint in the determination of the minimum antenna mast height for the lower antenna.

In any case, the methods consists of mathematical expressions and algorithm for determination of the various requisite parameters along with the minimum the transmitter and the receiver antenna mast heights. 


\section{Theoretical Background}

\subsection{Determination of the Minimum Antenna Mast Height When the Path Inclination Is not Equal to Zero, $\left(\mathrm{H}_{t} \neq \mathrm{H}_{r}\right)$ and the Higher Antenna Height $\left(\mathrm{H}_{r}\right)$ Is Known}

In this analysis, a communication link (figure 1) with the transmitter $(\mathrm{T})$ and the receiver $(\mathrm{R})$ at distance $\mathrm{d}$ apart is considered. it is assumed that the higher antenna is the receiver antenna and it is known. As such, $\mathrm{H}_{\mathrm{t}} \leq \mathrm{H}_{\mathrm{r}}$. If however, $\mathrm{H}_{\mathrm{t}}>\mathrm{H}_{\mathrm{r}}$, then the notation $\mathrm{r}$ for transmitter and $\mathrm{t}$ for receiver will have to be swapped, whereby the transmitter becomes the receiver and vice versa.

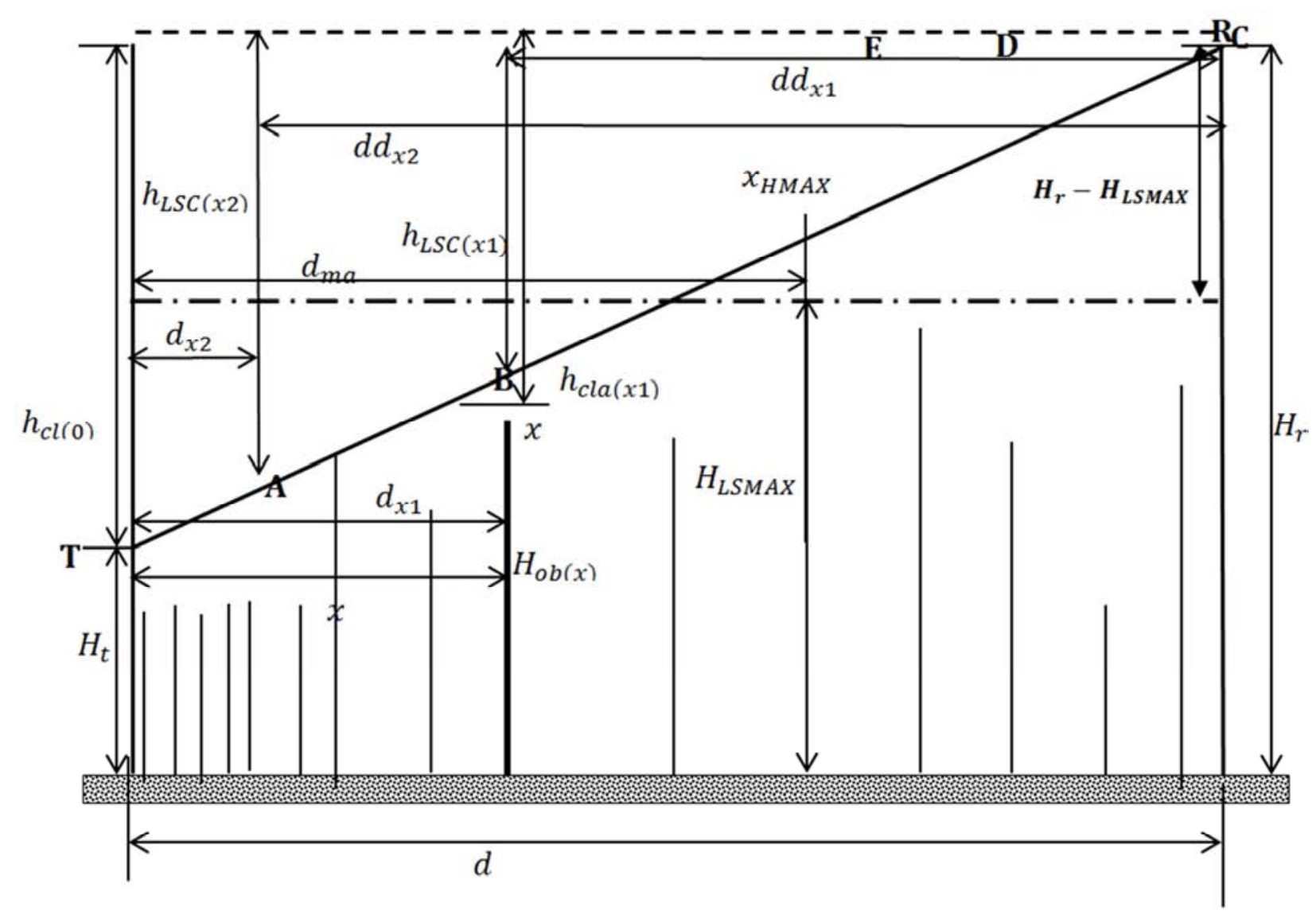

Figure 1. Model for determining the antenna mast height when the path inclination is not equal to zero.

Let $h_{\text {cla }(x)}$ be defined as the difference between the given receiver antenna height $\left(H_{r}\right)$ and the obstruction height at location $\mathrm{x}$ which is a distance $d_{x}$ from the transmitter. That means,

$$
h_{c l a(x)}=H_{r}-H_{o b(x)}
$$

Where

$h_{\text {cla }(x)}$ is the actual line of sight (LOS) clearance height (in $\mathrm{m})$ at point $\mathrm{x}$.

$h_{o b(x)}$ is the obstruction height (in $\mathrm{m}$ ) at point $\mathrm{x}$ measured from the ground level whereas $H_{o b(x)}$ is the obstruction height (in $\mathrm{m}$ ) at point $\mathrm{x}$ measured from the sea level, where;

$$
H_{o b(x)}=H_{r}-\left(h_{o b(x)}+H_{e b(x)}+H_{e l(x)}\right)
$$

$H_{e b(x)}$ is the height (in $\mathrm{m}$ ) of the earth bulge at location $\mathrm{x}$ between the transmitter and the receiver; it is given as $[8,-10]$;

$$
H_{e b(x)}=\frac{\left(d_{t(x)}\right)\left(d_{r(x)}\right)}{12.75 * K}
$$

At the transmitter and the receiver, $d_{t(x)}=0$, hence, $H_{e b(x)}=0$.

$H_{e l(x)}$ is the elevation (in $\mathrm{m}$ ) at point $\mathrm{x}$, which is a distance of $d_{t(x)}$ from the transmitter and a distance of $d_{r(x)}$ from the receiver.

Let $h_{L S C(x)}$ be defined as the expected line of sight height at point x. Basically, $h_{L S C(x)}$ gives the equation for line of sight in terms of $H_{r}$. At the transmitter, $\mathrm{x}=0, d_{x}=0$, and $h_{L S C(x)}=h_{L S C(0)}=h_{\text {cla }(0)}=H_{r}-H_{t}$.

$d_{x}$ is the distance from the transmitter to point $\mathrm{x}$. In addition, let $d d_{x}$ be the distance from the receiver to point $\mathrm{x}$. Then, $d d_{x}=-d_{x}$. Consider two points on the line of sight at location $\mathrm{x} 1$ and $\mathrm{x} 2$ (where location $\mathrm{x} 1$ is at a distance $d_{x 1}$ from the transmitter and a distance $d d_{x 1}$ from the receiver, Also, location $\mathrm{x} 2$ is at a distance $d_{x 2}$ from the transmitter and a distance $d d_{x 2}$ from the receiver). Then, by using similar triangle (in Figure 1 ) on triangles ARD and BRD, $h_{L S C(x 1)}$ (which is the expected line of sight clearance height at point $\mathrm{x} 1$ ) and $h_{\operatorname{LSC}(x 2)}$ (which is the 
expected line of sight clearance height at point $\mathrm{x} 2$ ) are related as follows:

Hence,

$$
h_{L S C(x 2)}=\left(\frac{d d_{x 2}}{d d_{x 1}}\right) h_{L S C(x 1)}
$$

In order to satisfy the line of sight clearance requirement at point $\mathrm{x}$ the following condition must be met:

$$
h_{L S C(x)} \leq h_{c l a(x)}-f r c l \text { for all } \mathrm{x}=0,1,2,3 \ldots n_{e} .
$$

Where $f r c l$ is the clearance of the Fresnel zone, $\mathrm{n}$ where [12-15];

$$
f r c l=\left(\frac{P_{(n)}}{100}\right)\left(r_{(n)}\right)
$$

Where

$$
\begin{gathered}
\mathrm{r}_{(n)}=\sqrt{\frac{n\left(\kappa\left(d_{t(x)}\right)\left(d_{r(x)}\right)\right)}{\left(d_{t(x)}+d_{r(x)}\right)}} ; \text { for } \mathrm{n}=1,2,3, \ldots \text { and } d_{t(x)}>> \\
\mathrm{r}_{(n, x)} \text { and } d_{r(x)}>>\mathrm{r}_{(n, x)}
\end{gathered}
$$

$\lambda$ in metres is given as;

$$
\Lambda=\frac{c}{f}
$$

$\mathrm{P}_{(\mathrm{n})}$ is the percentage clearance allowed for the Fresnel zone $\mathrm{n}$, given in \%. Normally, $60 \%$ clearance of Fresnel zone 1 is required. In that case, $\mathrm{n}=1$ and $\mathrm{P}_{(\mathrm{n})}=60 \%$

Initially, $x 1=x=0$, and $h_{L S C(x 1)}=h_{L S C(0)}=$ $h_{\text {cla }(0)}=H_{r}-H_{t}$. Also, at $\mathrm{x} 1=\mathrm{x}=0, d_{x}=0$ and $d d_{0}=$ $d-0=d$. In essence, with $h_{L S C(0)}=h_{c l a(0)}=H_{r}-H_{t}$, the line of sight clearance requirement is satisfied at $\mathrm{x} 1=\mathrm{x}=$ 0 . Then, $h_{L S C(x 2)}$ is computed for $\mathrm{x} 2=\mathrm{x} 1+1, \mathrm{x} 1+2$, $\mathrm{x} 1+3, \ldots, n_{e}$. At each point of $\mathrm{x} 2$, the line of sight clearance requirement conduction $h_{L S C(x 2)} \leq h_{\text {cla }(x 2)}$ is evaluated. If the condition is not satisfied, then, the current $\mathrm{x} 2$ becomes the $\mathrm{x} 1$ (that is, $\mathrm{x} 1=\mathrm{x} 2$ ) and the current $h_{\operatorname{LSC}(x 1)}$ becomes $h_{c l a(x 2)}$ (that is, $\left.h_{L S C(x 1)}=h_{c l a(x 2)}\right)$. Next, $h_{L S C(x 2)}$ is computed for $\mathrm{x} 2=\mathrm{x} 1+1, \mathrm{x} 1+2, \mathrm{x} 1+3, \ldots, n_{e}$. When all the points from $\mathrm{x}=0$ to $\mathrm{x}=n_{e}$ are considered, the transmitter height is adjusted based on the last value of $h_{L S C(x 1)}$ which is at a distance of $d d_{x 1}$ from the receiver. The adjustment is done as follows;

$$
\begin{aligned}
h_{L S C(0)} & =\left(\frac{d d_{0}}{d d_{x 1}}\right) h_{L S C(x 1)} \\
H_{t} & =H_{r}-h_{L S C(0)}
\end{aligned}
$$

The height (in meters) of the transmitter antenna mast measured from the ground is given as $h_{t \text { (mast) }}$ where;

$$
\mathrm{h}_{\mathrm{t} \text { (mast) }}=H_{t}-H_{e l t}=H_{r}-h_{L S C(0)}-H_{e l t}
$$

Where $H_{\text {elt }}$ is the elevation at the transmitter. The height (in meters) of the receiver antenna mast measured from the ground is denoted as $\mathrm{h}_{\mathrm{r} \text { (mast) }}$;

$$
\mathrm{h}_{\mathrm{r} \text { (mast) }}=H_{r}-H_{e l r}
$$

\subsection{The Procedure for Determining the Minimum Antenna Mast Height When the Path Inclination Is Not Equal to Zero and the Higher Antenna Height Is Known}

The following algorithm states the procedure for determining the minimum transmitter and receiver antenna mast height when the path inclination is not equal to zero and the higher antenna height is known.

Step 1: Input $H_{r}, H_{e l r}, H_{e l t}, d, n_{e}$

Step: $H_{t}=H_{\text {elt }}$

Step 2: $h_{L S C(0)}=h_{\text {cla }(0)}=H_{r}-H_{t}$.

Step 3: $d d_{0}=d$

Step 4: $\mathrm{x} 1=0$

Step 5: For $\mathrm{x} 2=\mathrm{x} 1$ to $n_{e}$ Increment 1

Step: Input $d_{x 1}, d_{x 2}, H_{o b(x 2)}$

Step: $d d_{x 1}=d-d_{x 1}$,

Step: $d d_{x 2}=d-d_{x 2}$,

Step 6: $h_{L S C(x 2)}=\left(\frac{d d_{x 2}}{d d_{x 1}}\right) h_{L S C(x 1)}$

Step 7: $h_{c l a(x 2)}=H_{r}-H_{o b(x 2)}=H_{r}-\left(h_{o b(x 2)}+\right.$ $\left.H_{e b(x 2)}+H_{e l(x 2)}\right)$

Step 8: if $\left(h_{\operatorname{LSC}(x 2)}>h_{\text {cla }(x 2)}\right)$ then

Step 9: $h_{L S C(x 1)}=h_{\operatorname{cla}(x 2)}$

Step 10: $\mathrm{x} 1=\mathrm{x} 2$

Step 11: Endif

Step 12: Next x2

Step 13: $h_{L S C(0)}=\left(\frac{d d_{0}}{d d_{x 1}}\right) h_{L S C(x 1)}$

Step 14: $H_{t}=H_{r}-h_{L S C(0)}$

Step 15: $\mathrm{h}_{\mathrm{t}(\text { mast })}=H_{t}-H_{\text {elt }}=H_{r}-h_{L S C(0)}-H_{\text {elt }}$

Step 16: $\mathrm{h}_{\mathrm{r} \text { (mast) }}=H_{r}-H_{\text {elr }}$

Step 17: End

\section{Results and Discussions}

The LOS link parameters are used in the computation are; path length $=38887.6 \mathrm{~m}$, frequency $=3 \mathrm{GHz}$, effective earth radius factor (k-factor) $=1.33333$ and obstruction height (hob) $=10 \mathrm{~m}$. The receiver antenna is assumed to be $20 \mathrm{~m}$ above the maximum height of the tip of the obstruction and the specified minimum LOS percentage clearance with respect to Fresnel zone 1 is $60 \%$. Some of the elevation profile is given is Table 1 . The maximum elevation of the obstruction from sea level (that is, maximum $\left(H_{o b(x)}\right) 146.62 \mathrm{~m}$ and it occurred at a the distance of $14306.98 \mathrm{~m}$ from the transmitter. The receiver antenna is assumed to be $20 \mathrm{~m}$ above maximum $\left(H_{o b(x)}\right)$. So, the receiver antenna is $166 \mathrm{~m}$ while from the results the transmitter is obtained as $135.35 \mathrm{~m}$ high.

In table 1 the minimum percentage clearance of $60 \%$ with respect to Fresnel zone 1 occurred at the location of the maximum height of the tip of the obstruction which is a distance of $14306.98 \mathrm{~m}$ from the transmitter. The radius of the first Fresnel zone at that point is $30.07 \mathrm{~m}$ and the LOS clearance height at that point is $-18 \mathrm{~m}$ which gives the percentage clearance of $60 \%$ at that point. The $60 \%$ percentage clearance tallies with the $60 \%$ clearance specified at the link design stage. 
Table 1. The Antenna Mast Computation Result.

\begin{tabular}{|c|c|c|c|c|c|c|c|}
\hline $\begin{array}{l}x \text {, Elevation } \\
\text { Point }\end{array}$ & $\begin{array}{l}\mathrm{dx}, \text { Distance } \\
\text { (m) }\end{array}$ & $\begin{array}{l}\text { hel (x) Elevation } \\
(\mathrm{m})\end{array}$ & $\begin{array}{l}\text { Heb (x)Earth } \\
\text { Bulge (m) }\end{array}$ & $\begin{array}{l}\text { Hx, LOS } \\
\text { Height (m) }\end{array}$ & $\begin{array}{l}\text { hLsc (x), LOS } \\
\text { Clearance height (m) }\end{array}$ & $\begin{array}{l}\text { r1, radius Of The First } \\
\text { Fresnel Zone (m) }\end{array}$ & $\begin{array}{l}\text { P (x, } 1) \text {, Percentage } \\
\text { Clearance Of The First } \\
\text { Fresnel Zone } \%\end{array}$ \\
\hline 1 & 0 & 89.8 & 0 & 135.3 & -35.5 & 0 & - \\
\hline 24 & 1750.3 & 78 & 3.82 & 136.7 & -44.9 & 12.93 & -347.4 \\
\hline 72 & 5403.2 & 92.3 & 10.64 & 139.6 & -26.6 & 21.57 & -123.5 \\
\hline 96 & 7229.6 & 97 & 13.46 & 141 & -20.6 & 24.26 & -84.8 \\
\hline 120 & 9056 & 94.4 & 15.89 & 142.5 & -22.2 & 26.36 & -84.4 \\
\hline 168 & 12708.9 & 90.5 & 19.57 & 145.4 & -25.3 & 29.25 & -86.5 \\
\hline 189 & 14307 & 97.9 & 20.69 & 146.6 & -18 & 30.07 & -60 \\
\hline 192 & 14535.3 & 94 & 20.82 & 146.8 & -22 & 30.17 & -72.9 \\
\hline 240 & 18188.1 & 92.3 & 22.15 & 149.7 & -25.2 & 31.11 & -81.1 \\
\hline 256 & 19405.7 & 92.2 & 22.24 & 150.6 & -26.2 & 31.18 & -83.9 \\
\hline 264 & 20014.6 & 89.4 & 22.22 & 151.1 & -29.5 & 31.17 & -94.7 \\
\hline 288 & 21841 & 30.8 & 21.9 & 152.6 & -89.8 & 30.94 & -290.3 \\
\hline 336 & 25493.8 & 29.8 & 20.09 & 155.4 & -95.5 & 29.63 & -322.4 \\
\hline 384 & 29146.7 & 49.9 & 16.7 & 158.3 & -81.7 & 27.02 & -302.3 \\
\hline 408 & 30973.1 & 20 & 14.42 & 159.8 & -115.3 & 25.11 & -459.4 \\
\hline 432 & 32799.5 & 22.4 & 11.75 & 161.2 & -117.1 & 22.66 & -516.6 \\
\hline 480 & 36452.4 & 36.7 & 5.22 & 164.1 & -112.2 & 15.11 & -742.7 \\
\hline 504 & 38278.8 & 29 & 1.37 & 165.5 & -125.2 & 7.74 & -1617.2 \\
\hline 512 & 38887.6 & 48.9 & 0 & 166 & -107.1 & 0 & - \\
\hline
\end{tabular}

When the elevation height is subtracted from the antenna height, then the transmitter antenna mast height is $45.51 \mathrm{~m}$ while the receiver antenna mast height is $117.1 \mathrm{~m}$. Also, given the receiver antenna height is $166.6 \mathrm{~m}$ and transmitter antenna height is $135.35 \mathrm{~m}$, the transmitter antenna is lower than the receiver antenna. The transmitter is also below the maximum height of the tip of the obstruction which is $146.62 \mathrm{~m}$ high. The path inclination is $\frac{\left|H_{r}-H_{t}\right|}{d}=\frac{|166.6-135.35|}{38.88759}=0.804$, where $\mathrm{d}$ is in $\mathrm{km}$ and $H_{r}$ and $H_{t}$ are in $\mathrm{m}$.

\section{Conclusion}

In this paper, a second method for determination of the minimum antenna mast height when the path inclination is not equal to zero and the higher antenna height is known is presented. In the first method,(not presented here), none of the antenna height is known. In this second paper, the height of one of the antenna is known, particularly, the antenna that is above the maximum obstruction height. This places further constraint in the determination of the minimum antenna mast height for the lower antenna. In this paper, both the mathematical models and the algorithm are presented along with sample numerical example using path profile data for a line of site microwave communication link.

\section{References}

[1] Thakur, A., Kamboj, S., \& Scholar, P. G. (2016). Transmission and Optimization of a $3 \mathrm{G}$ Microwave Network at $18 \mathrm{GHz}$. International Journal of Engineering Science, 5622.

[2] Kildal, P. S. (2015). Foundations of Antenna Engineering: A Unified Approach for Line-of-sight and Multipath. Artech
House.

[3] Boccardi, F., Heath, R. W., Lozano, A., Marzetta, T. L., \& Popovski, P. (2014). Five disruptive technology directions for 5G. IEEE Communications Magazine, 52 (2), 74-80.

[4] Al Mahmud, M. R. (2009). Analysis and planning microwave link to established efficient wireless communications (Doctoral dissertation, Blekinge Institute of Technology).

[5] Sim, C. Y. D. (2002). The propagation of VHF and UHF radio waves over sea paths (Doctoral dissertation, University of Leicester).

[6] Shaver, R. J., Saville, M. A., \& Park, J. (2016, May). Modeling terrain profiles from digital terrain elevation data and national land cover data. InSPIE Defense+Security (pp. 98430L-98430L). International Society for Optics and Photonics.

[7] Kvicera, M., Pechac, P., Valtr, P., Korinek, T., Kvicera, V., Grabner, M., \& Martellucci, A. (2015). Influence of Input Terrain Profile Resolution on Diffraction Modeling. IEEE Antennas and Wireless Propagation Letters, 14, 1318-1321.

[8] Dalbakk, L. E. (2014). Antenna System for Tracking of Unmanned Aerial Vehicle.

[9] Kang, Y. H. (2015). Analysis on the Path Length of M/W Access Link for Mobile Backhaul Design. The Journal of Advanced Navigation Technology, 19 (6), 607-613.

[10] Jicha, O., Pechac, P., Kvicera, V., \& Grabner, M. (2013). Estimation of the radio refractivity gradient from diffraction loss measurements. IEEE Transactions on Geoscience and Remote Sensing, 51 (1), 12-18.

[11] Adediji, A. T., Mandeep, J. S., \& Ismail, M. (2014). Meteorological Characterization of Effective Earth Radius Factor (k-Factor) for Wireless Radio Link Over Akure, Nigeria. Mapan, 29 (2), 131-141. 
[12] Jouad, A., Bor, J., Lafond, O., \& Himdi, M. (2016, April). Millimeter-wave fresnel zone plate lens based on foam gradient index technological process. In 2016 10th European Conference on Antennas and Propagation (EuCAP)(pp. 1-4). IEEE.

[13] Ahamed, M. M., \& Faruque, S. (2015, May). Path loss slope based cell selection and handover in heterogeneous networks. In 2015 IEEE International Conference on Electro/Information Technology (EIT) (pp. 499-504). IEEE.
[14] Mazar, H. (1991, March). LOS radio links, clearance above tall buildings. InElectrical and Electronics Engineers in Israel, 1991. Proceedings., 17th Convention of (pp. 145-148). IEEE

[15] Sen, S. (2006). Topology planning for long distance wireless mesh networks (Doctoral dissertation, Indian Institute of Technology, Kanpur). 